\title{
Conceptual development of the vertical axis wind turbine with movable blades
}

\author{
George André Souza Santiago ${ }^{a}$, Mario Orestes Aguirre Gonzáleza , Willmari Dayana Suarez Hernandez \\ Ramiro Gustavo Ramirez Camacho ${ }^{b}$ \\ aPrograma de Pós-graduaç̃õo em Engenharia de Produção, Universidade Federal do Rio Grande do Norte \\ Instituto de Engenharia Mecânica, Universidade Federal do Itajubá. \\ e-mails: geosantiago@yahoo.com.br; mario@ct.ufrn.br; marwill13@hotmail.com; ramirez@unifei.edu.br
}

\begin{abstract}
This paper, through of approach of Product Development Process, characterizes the development phases of a new concept of vertical axis wind power turbine. The conceptual model used serves as a guide in the design, management and implementation of product research and development. The use of a model facilitates the replication, evolution and error handling of a new concept. Product development methodology were applied in laboratory and the results prove the efficiency of the proposed prototype in comparison to existing technologies.
\end{abstract}

Keywords: conceptual project, wind turbine, wind energy.

\section{Introduction}

The wind energy as a source of energy generation free of greenhouse gas emission has had in the last twenty-five years a technological development and economic competitiveness, which have become the most attractive investment option in energy generation. It is still considered that this type of energy source presents a low environmental impact if compared to other electric generation sources (GONZÁLEZ; GONÇALVES; VASCONCELOS, 2017).

The wind power capacity achieved in $2015432,9 \mathrm{GW}$ with a growing rate of more than $17 \%$, being the Popular Republic of China the leader ahead of the United States, Germany, India, Spain, UK, and Canada, respectively. China itself installed around $30 \mathrm{GW}$ in new projects.

It is estimated that in 2020, according to GWEC (Global Wind Energy Council), the world will have 12\% of energy generated by the wind power and it is expected to double the wind energy capacity installed across the world. To achieve this significant development, it is expected a gradual decreasing the cost of the energy produced by the wind power, especially in on-shore installation sites, which will turn this alternative each time more competitive (GLOBAL..., 2015). The cost of implementation, determined by criteria including wind availability, turbine performance, and plant efficiency, is measured in US/kWh-year, i.e., how much money is spent in order to obtain one $\mathrm{kWh}$ of electric power each year. Several technologies exist for this purpose and it must be considered involving the R\&D in the decisions that aim to the declining of the costs and the increasing of technology efficiency (FALANI, 2014). These prognoses will be achieved exclusively by the continuous investment in researching, development, and innovation.

For this purpose, the development of new products happens by the innovation. According to Bornia and Lorandi (2008), the essential elements of a production system have direct implications in the process of product development (PDP). At the forefront to diversify the options of wind power turbines and turn the process of wind energy generation into more efficient, clean and low cost, the turbines developed to distributed generation are presented as a promising way for renewable energy.

With this overview, the Vertical Axis Wind Turbines (VAWT) that are the wind power turbines whose axis of rotation is oriented to the same direction of the tower that supports the structure of the rotor, in other words, in a direction that is perpendicular to the direction of the wind movement, fill the basic requirements.

From the point of view of product innovation, this study aims to characterize the process of development of a new wind power turbine by the use of a reference model and demonstrate by experimental mode the capacity of capturing the wind power and transforming into electric power.

\section{Product development process}

The development of a new product involves a large number of criteria, including time limit, quality of products, production costs, product requirements. For this reason, a good "product development process" (PDP) is required. 
According to Davenport (1994) "process" is a specific disposition of the work activities in the period, with (1) a beginning, an end and (2) inputs and outputs clearly defined: a structure to an action. For Valle (2008), "process" is understood as the set of actions in which inputs (e.g., materials, information, source, and human force) generate outputs which are desired or not desired (e.g., materials, source, information, human force in a state different than it began, pollution). To Rozenfeld et al. (2006), "process" includes a set of internally organized activities which aim to produce goods or services for a specific type of client.

The product development process (PDP) considers the competitive strategies associated with the technological and marketing strategies, through integration of the activities and information related to the specifications definitions of the project and the process, for converting into manufactured products until the discontinuity or withdraw of the same products from the market (ROZENFELD et al., 2006).

\subsection{Model and tools covered on the product development}

Due to the uncertainties that characterize the PDP, Rozenfeld et al. (2006) suggested the formalization, structuring, and systematization of the PDP through a reference model, called "Unified Model", that is presented in Figure 1.

The reference model divides the PDP in three macro-phases, namely: i) pre-development, the project portfolio to be developed; ii) development, which emphasizes the aspects corresponding to the definition of the project itself, the characteristics and specifications and form of production; and, iii) post-development, whose main activities are the monitoring of the product and the documentation of the improvements during its life cycle (ROZENFELD et al., 2006).
"Tools" are used in order to assist the activities within the PDP. From the literature, the more common tools used in PDP include QFD - Quality Function Deployment (AKAO, 1990); FMEA - Failure Modes and Effects Analysis - (ROZENFELD et al., 2006); DFA - Design of Assembly (HUANG, 1996) and others. These tools may be employed, with little or no adaptation, for the development of a VAWT.

\section{Wind turbine technical fundamentals}

A wind turbine is divided into three systems: (1) wind power capturing system, (2) transmission and electric generation system and (3) controlling system. Each of these systems will be briefly described below.

\subsection{Wind power capturing system}

The capturing system of the wind power consists of the turbine and the tower. According to the Center of Reference to Wind and Solar Energy Sérgio de Salvo Brito - CRESESB (CENTRO..., 2008), there are two traditional configurations for the windmill: with vertical axis rotor and with horizontal axis rotor.

- The vertical axis rotor, the majority, is powered by supporting forces and consists of curved blades (two or three) with an aerodynamic profile, tied by the two ends of the vertical axis;

- The horizontal axis rotor is the most commercially used model (LAYTON, 2011), It uses aerodynamic drag forces which obstruct wind movement. There are also lift forces which act perpendicular to the flow.

Modern wind turbines with horizontal axis rotors have three blades connected to a hub which, in turn is connected

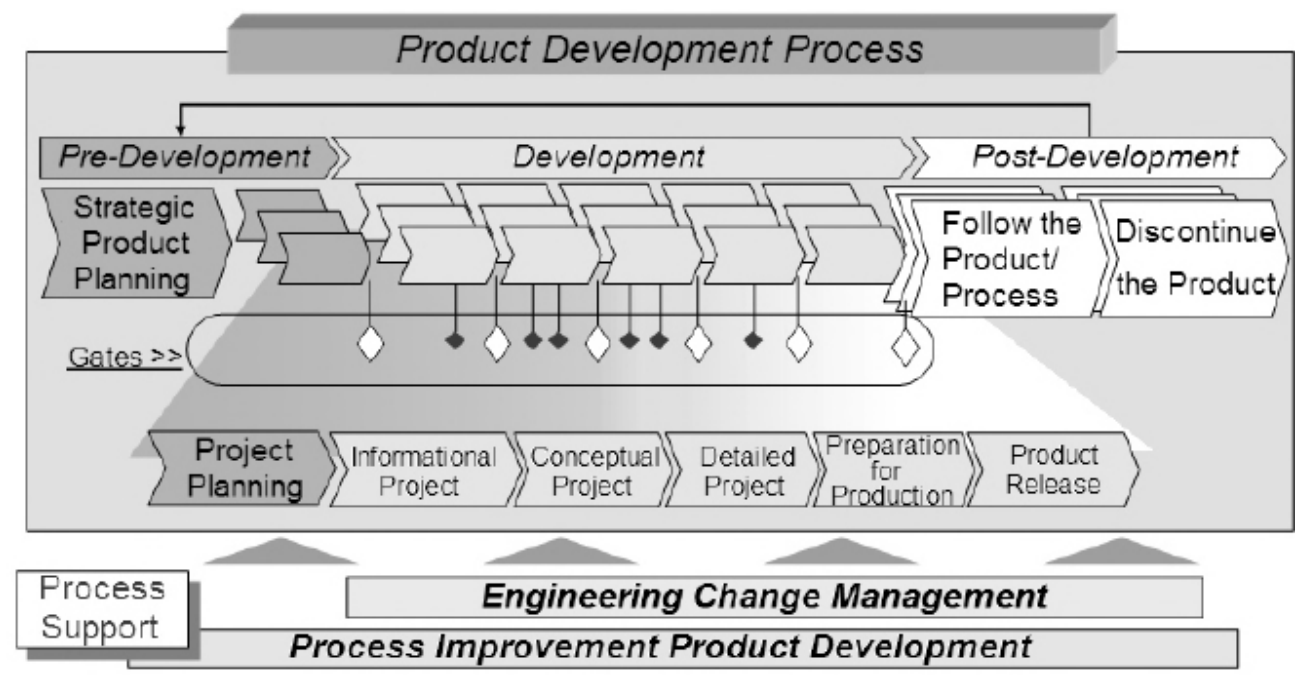

Figure 1. Unified Model for Product Development Process. 
to a gearbox by means of an axis (there are exceptions, however machines which use multipolar generators and which do not have a gearbox). The blades are aerodynamic profiles responsible for the interaction to the wind, converting part of their kinetic energy into mechanical work.

The hub contains the bearings which fix the positions of the revolving blades. It also accommodates the mechanisms and motors for adjusting the angle of attack of all blades. The axis is responsible for coupling the hub to the generator, transferring the kinetic energy of the blades to the generator (CENTRO..., 2008).

Windmills are also classified according to the power that they generate (ERIKSSON; BERNHOFF; LEIJON, 2008; LEHMANN; KOENEMANN, 2005; SILVA, 2001): small-sized (up to $50 \mathrm{~kW}$ of power), medium-sized (up to $50 \mathrm{~kW}$ to $1 \mathrm{MW}$ of power) and large (more than $1 \mathrm{MW}$ of power). In 2012 in Brazil, National Electric Energy Agency (ANEEL) added two nomenclatures regarding power, mini-generator (up to $75 \mathrm{~kW}$ of power) and micro-generator (up to $75 \mathrm{~kW}$ to $5 \mathrm{MW}$ of power) (FALANI, 2014).

\subsection{Transmission and electric power generation system}

The transmission system is designed to transmit the mechanical energy of the revolving turbine blades to the electrical generator. It may or may not include a gearbox. Because both wind speed and wind direction are variable, it is not guaranteed that the mechanical energy being transformed is constant in time. The generator and gearbox are located in an assembly on the tower called the nacelle.

\subsection{Controlling system}

The controlling system contains mechanisms which are designed to control rotor orientation, speed, electrical load, among others. There is an enormous variety of mechanisms that can be mechanical (speed, pace, brake), aerodynamical (rotor position) or electrical (load control).

Pace control (pitch control) is achieved by an electrical controller which monitors turbine motion for the purpose of power control. When the wind speed exceeds $72 \mathrm{~km} / \mathrm{h}$, power generation will be excessive, so the controller commands that the blades change their pace so that they are misaligned with the wind.

Passive loss of aerodynamic efficiency (stol) is accomplished as follows. The blades are mounted on the rotor at a fixed angle but are designed so that the blade's own twisting applies braking when the wind is excessive. The blades are also arranged at an angle so that winds above a certain speed will cause turbulence on the opposite side of the blade, inducing loss of aerodynamic efficiency.

\section{Characterization of the prototype in the PDP approach}

Here we outline the use of the PDP approach in our study of Vertical Axis Wind Turbines (VAWTs). Our method will be deductive, seeking to verify in practice if our method results in a prototype that achieves pre-established standards. The VAWT prototype used in this study was the Dulcetti Eolic Converter (DEC). Its main feature consists of aerodynamic plates which are alternately opened and closed by the action of frontal wind, producing movement in the vertical axis.

\subsection{Informational project}

In general, this aspect of the project is concerned about the characteristics that the product must have in order to supply the basic needs of the project, along with details of the required equipment. In our study, it can be defined as the basic requirements of the wind turbine in order to capture the wind energy in a satisfactory way and transform it into electrical energy, as shown in Table 1.

\subsection{Conceptual project}

On the phase of the Conceptual Project, the project staff activities are related to the search, to the creation, representation and selection of solutions for the project problem (ROZENFELD et al., 2006).

In this phase, a conception of the product which satisfactorily responds to the basic, technical requirements is shown in Table 2.

\subsection{Preliminary project}

This phase is concerned with the overall structure of the process in which a product is constructed from the components identified in the previous item, i.e., the Conceptual Project. It will employ drawings of the

Table 1. Classification of wind turbines.

\begin{tabular}{|c|c|c|}
\hline System & $\begin{array}{l}\text { Classification of } \\
\text { wind turbines }\end{array}$ & Settings \\
\hline \multirow{15}{*}{$\begin{array}{l}\text { Wind Energy } \\
\text { Capture System }\end{array}$} & \multirow{2}{*}{ Rotor axis } & Horizontal \\
\hline & & Vertical \\
\hline & \multirow{4}{*}{ Number of blades } & Mono-blade \\
\hline & & Double blades \\
\hline & & Triple blades \\
\hline & & Multiple blades \\
\hline & Radius of the rotor & Miscellaneous \\
\hline & \multirow{2}{*}{$\begin{array}{l}\text { Location of the wind } \\
\text { turbine }\end{array}$} & Onshore \\
\hline & & Offshore \\
\hline & \multirow{5}{*}{ Power } & Large \\
\hline & & Medium \\
\hline & & Small \\
\hline & & Mini-aerogenerator \\
\hline & & Micro-aerogenerator \\
\hline & Height of the nacelle & Miscellaneous \\
\hline \multirow{2}{*}{$\begin{array}{c}\text { Electrical generation } \\
\text { system }\end{array}$} & \multirow{2}{*}{ Type of generator } & Synchronous \\
\hline & & Asynchronous \\
\hline \multirow[b]{2}{*}{ Control system } & \multirow[b]{2}{*}{ Type of control } & Control of Pitch \\
\hline & & $\begin{array}{l}\text { Control Liabilities } \\
\text { of lost of efficiency } \\
\text { aerodynamics (Stol) }\end{array}$ \\
\hline
\end{tabular}


sets, subsets, and components that will be used for tests. This stage is responsible for the organization of the product assembly and its maintenance. It will be useful for standardization, for testing and for the determination of solutions when defects in the project are detected.

Table 2. Classification of wind turbines.

\begin{tabular}{|c|c|c|}
\hline System & $\begin{array}{c}\text { Classification of wind } \\
\text { turbines }\end{array}$ & Settings \\
\hline \multirow{7}{*}{$\begin{array}{l}\text { Wind Energy } \\
\text { Capture } \\
\text { System }\end{array}$} & Rotor axis & Vertical \\
\hline & Number of blades & Multiple blades \\
\hline & Radius of the rotor & Miscellaneous \\
\hline & $\begin{array}{l}\text { Location of the wind } \\
\text { turbine }\end{array}$ & Onshore \\
\hline & \multirow{2}{*}{ Power } & Medium \\
\hline & & Micro-aerogenerator \\
\hline & Height of the nacelle & Miscellaneous \\
\hline $\begin{array}{l}\text { Electrical } \\
\text { generation } \\
\text { system }\end{array}$ & Type of generator & Asynchronous \\
\hline $\begin{array}{l}\text { Control } \\
\text { system }\end{array}$ & Type of control & $\begin{array}{l}\text { Control Liabilities } \\
\text { of lost of efficiency } \\
\text { aerodynamics (Stol) }\end{array}$ \\
\hline
\end{tabular}

\subsection{Detailed project}

This fourth stage of the PDP process involves a breakdown of prototype assembly and performance tests. The technical specifications are defined in the technical requirements in the beginning of the project.

\subsubsection{Assembly of the test platform}

The Platform for open-air Aerodynamic Testing was installed at the Campus of Federal University of Itajubá, (UNIFEI) Brazil, which scheme is shown in Figure 2.

One of the components of the platform is an air generator. Air flows are generated by a belt-driven axial fan, $D=2.0(\mathrm{~m})$. The fan is powered by a three-phase electric motor with the following features: Electric Power $=125$ cheval vapor $(\mathrm{cv})$ $=92 \mathrm{~kW} ; 220 \mathrm{~V}$ and $1800 \mathrm{rpm}$ rotation.

In order to establish the characteristics of the fan and to establish a specific position for the sonic anemometer, several tests were performed which involved a survey of the flow speed profile in the cross-section of the upstream tunnel of the $2 \mathrm{~m}$-axial fan, and a comparison between the Prandtl Tube data of the sonic anemometer and the portable
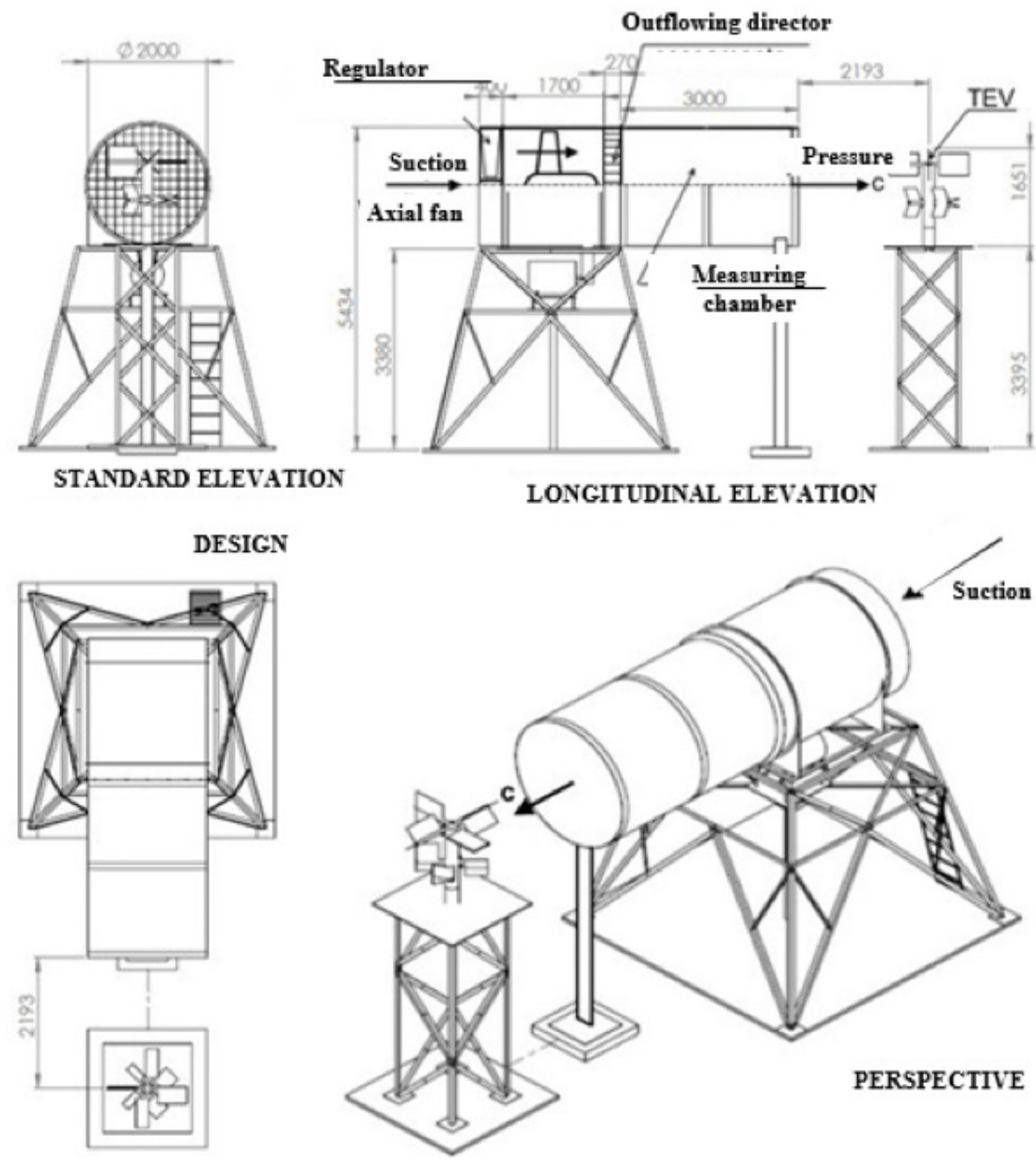

Figure 2. Wind Turbine Test bench from UNIFEI's Campus. 
anemometer. Initially, a maximum scan of $400(\mathrm{~mm})$ with Prandtl Tube was used. These tests established that the $35 \mathrm{~cm}$ position represented the most stable position for measuring the speed with the guarantee that the magnitude of the measured speed would be close that of the prototype.

\subsubsection{Experimental results}

The power coefficient $(\mathrm{Cp})$ was introduced by Betz's theory. The Betz limit indicates that even for the best wind turbines ( 2 or 3 blades of horizontal axis turbines), only a maximum of $59 \%$ of the wind energy is recovered, which means that maximum (theoretical) $\mathrm{Cp}$ is, approximately 0.59 . For an actual application, this coefficient is in the range of 0.2 to 0.4 at the most.

For comparison purposes, Figure 3 shows Betz limit (Power coefficient - Cp versus Tip speed ratio - tsr) with the different types of wind turbines. Then, in Figure 4 we present the result obtained from the tests with the developed prototype.

The experimental test was carried out by stabilizing the wind velocity (flow controller), changing the loads in the prototype with the use of variable resistances in order to establish a rotation field for each wind speed and the velocity values were acquired wind speed, prototype rotation, and torque.

Velocities below $3.95 \mathrm{~m} / \mathrm{s}$ could not overcome frictional forces to start any rotation movement in the prototype. For velocities above $12 \mathrm{~m} / \mathrm{s}$, with a maximum load and rotation of $42 \mathrm{rpm}$, the prototype suffered structural damage - the damping mechanisms and blade stops were released from the panels. This led us to conduct our experiments using four wind speeds, a minimum speed of $3.95 \mathrm{~m} / \mathrm{s}$, a nominal speed of $4.11 \mathrm{~m} / \mathrm{s}$, a moderate speed of $6.99 \mathrm{~m} / \mathrm{s}$ and a maximum speed of $10.99 \mathrm{~m} / \mathrm{s}$.

The Figure 4 shows the variation of the power coefficient based on the tip speed ratio, $\lambda$, for constant wind speed. We note that for a fixed $\lambda$ value, the power coefficients are lower for higher speeds, indicating that this type of turbine has a higher efficiency at lower wind speeds.

In Figure 5 are plotted the power coefficients as a function of rotation for different loads, which allows the estimation of the turbine operating field as a function of rotation, where the highest $\mathrm{Cp}$ power coefficient values were found with rotation values between $9 \mathrm{rpm}$ and $23 \mathrm{rpm}$.

In Figure 6 is plotted the variation of the power coefficient $\mathrm{Cp}$ of the DEC as a function of the incident wind velocity at approximately constant blade rotational speed (between 3.4 and $5 \mathrm{~m} / \mathrm{s}$ ) At a wind speed slightly greater than $4 \mathrm{~m} / \mathrm{s}$, we observe a Cp value of 25.44 .

In Figure 7 are shown plots of power coefficients Cp vs. tip speed ratios $\lambda$ for a number of commercially-available wind turbines, including the experimental results for the Dulcetti Eolic Converter (DEC) obtained in this study. From the

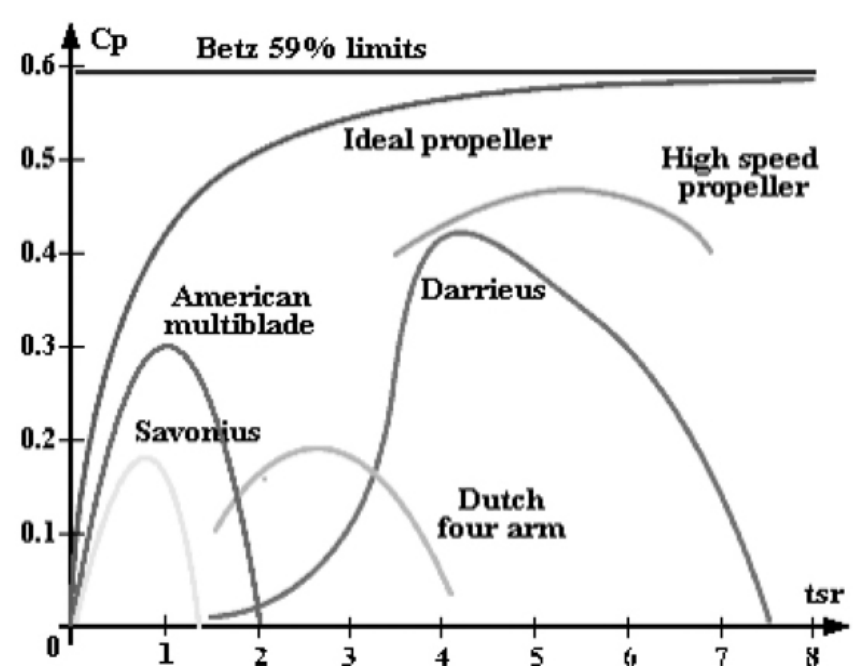

Figure 3. Comparison of the Betz limit with the different types of wind turbines.

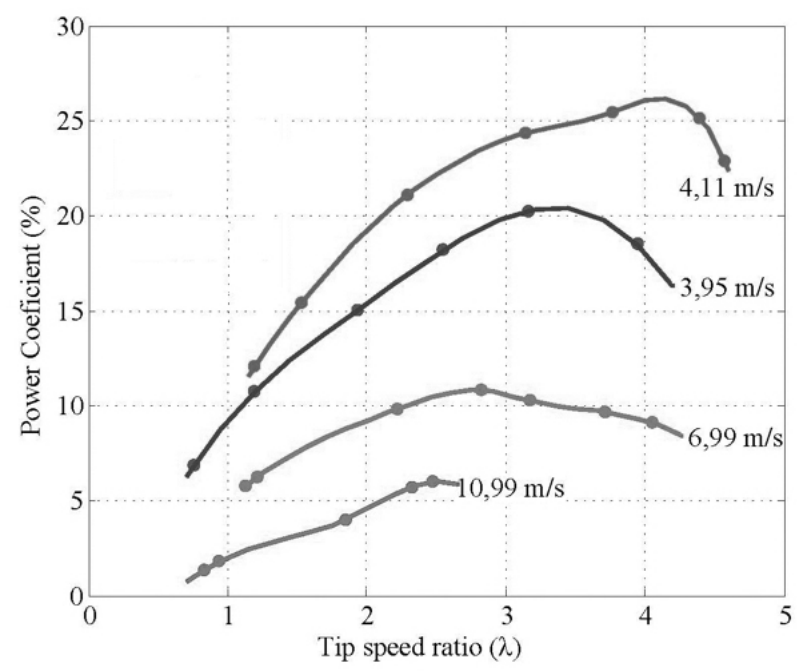

Figure 4. Graph of the power coefficient based on $\lambda$.

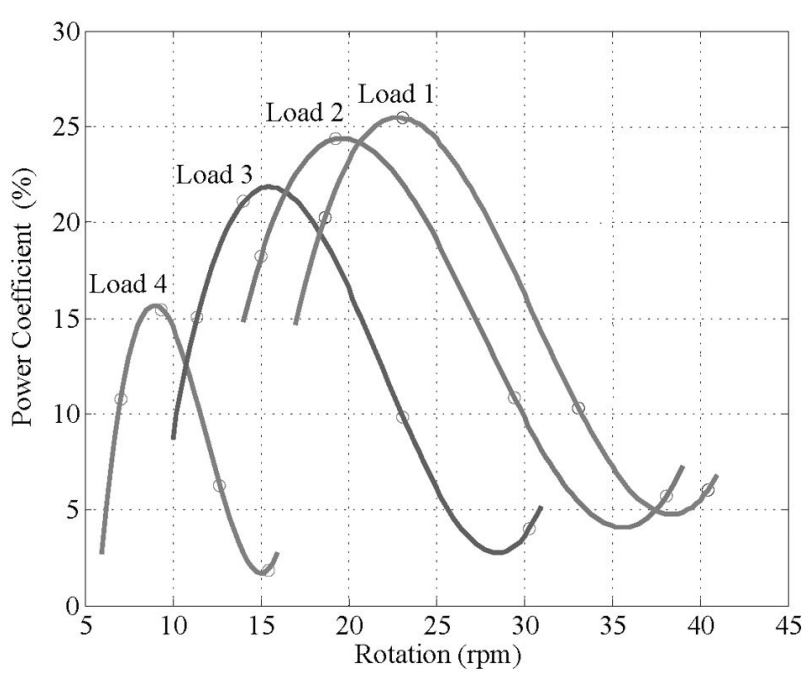

Figure 5. Graph of the power coefficient based on the rotation. 


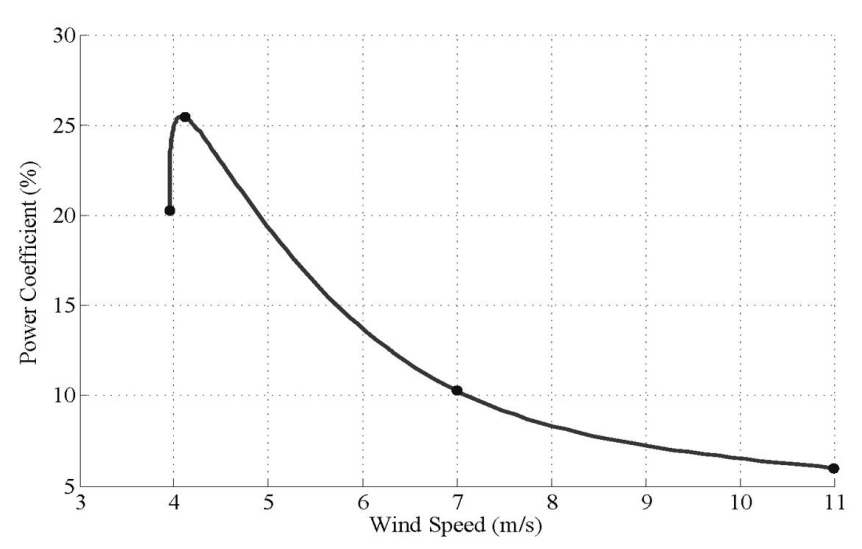

Figure 6. Graph of the power coefficient based on the wind speed.

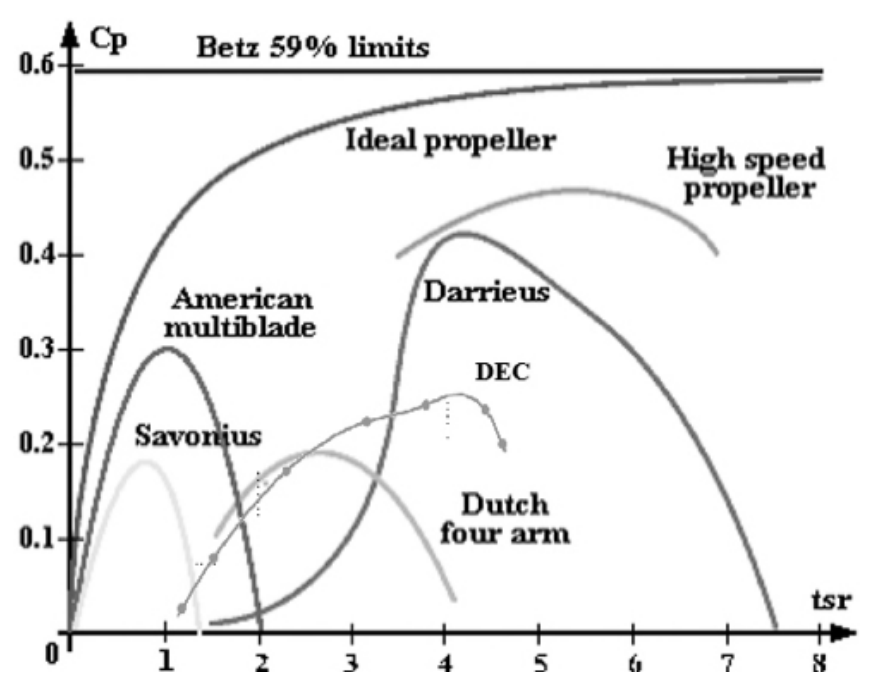

Figure 7. $\mathrm{Cp}$ vs $\lambda$ of different wind turbines.

graph, we see that the DEC prototype has characteristics that are similar to other vertical axis turbines that are currently available.

The experimental test carried out during the development of this work allowed a deep understanding of the studied subject. Several considerations were taken, the results of the experimental results of the DEC that have been made using the equipment carefully developed. Forces applied to the turbine during its operation are intense and complex to quantify, and a existence of phenomena, such as a vibration, directly affect the result. The instruments used to solve the desired patterns.

The experimental results of the DEC, performed in the laboratory of wind power turbines at the UNIFEI campus, represented an important test for the prototype that was the object of study in this project, observing general problems in the mechanical design of the turbine, as well as high levels of noise and vibration during operation, problems that may be solved in the stage of product development, aiming to improve the efficiency of the turbine, converting this new technology in a competitive one when compared to others technologies with similar power coefficients.

\section{Final considerations}

The use of a project development model, especially in the characterization stages and the experimental test used in this project, allowed a deep understanding of the studied theme. This study concluded that the achievement of the experimental results of the DEC should be made using carefully developed equipment in order to obtain data so that it can be compared with existing turbines.

Tests under real conditions are complex, mainly due to the variable nature of the wind. Thus, the system developed for the real-time DEC test must be equipped with automated instruments that allow data collection for long periods of time without an operator display, the turbine itself must be prepared to withstand all conditions, keeping outdoors for long periods.

Therefore, it is considered that the result was successful since the propositions were answered within the basic requirements of the product development process and proving the efficiency of the prototype. In turn, it provides an opening for a theoretical and numerical study making it possible to quantify the behavior of a vertical axis wind turbine.

\section{References}

AKAO, Y. Quality function deployment: integrating customer requirements into products. Portland: Productivity Press, 1990.

BORNIA, A. C.; LORANDI, J. A. O processo de desenvolvimento de produtos compartilhado na cadeia de suprimentos. Revista da FAE, v. 11, n. 2, p. 35-50, 2008.

CENTRO DE REFERÊNCIA PARA ENERGIA SOLAR E EÓLICA SÉRGIO BRITO - CRESESB. Energia eólica: princípios e tecnologias. Rio de Janeiro, 2008. Available from: <http://www.cresesb.cepel.br/tutorial/tutorial eolica_2008_e-book.pdf>. Access in: 1 Nov 2016.

DAVENPORT, T. Reengenharia de processos: como inovar na empresa através da tecnologia da informação. Rio do Janeiro: Campus, 1994.

ERIKSSON, S.; BERNHOFF, H.; LEIJON, M. A. T. S. Evaluation of different turbine concepts for wind power. Renewable \& Sustainable Energy Reviews, v. 12, n. 5 , p. $1419-1434,2008$. http://dx.doi.org/10.1016/j. rser.2006.05.017.

FALANI, S. Prospecção tecnológica para geração de energia eólica. 2014. 123 f. Dissertação (Mestrado em Engenharia 
de Produção)-Universidade Federal do Rio Grande do Norte, Natal, 2014.

GLOBAL WIND ENERGY COUNCIL - GWEC. Global wind report: annual market update. Brussels, 2015.

GONZÁLEZ, M.; GONÇALVES, J.; VASCONCELOS, R. Sustainable development: case study in the implementation of renewable energy in Brazil. Journal of Cleaner Production, v. 142, n. 1, p. 461-475, 2017. http://dx.doi. org/10.1016/j.jclepro.2016.10.052.

HUANG, G. Design for $\mathbf{X}$ : concurrent engineering imperatives. London: Chapman \& Hall, 1996.

LAYTON, J. Como funciona a energia eólica: a moderna tecnologia de geração eólica. UOL, 2011. Available from:
$<$ http://ambiente.hsw.uol.com.br/energia-eolica1.htm>. Access in: 24 May 2016.

LEHMANN, K.; KOENEMANN, D. Chancen der Kleinen. Alemanha: Sonne, Wind \& Warme, 2005. p. 23.

ROZENFELD, H. et al. Gestão de desenvolvimento de produtos: uma referência para a melhoria do processo. São Paulo: Saraiva, 2006.

SILVA, E. Metodologia da pesquisa e elaboração de dissertação. Florianópolis: Laboratório de Ensino a Distância, UFSC, 2001.

VALLE, R. Pós-Fordismos. Rio do Janeiro: [s.n.], 2008. Obra não publicada. 